\title{
Effect of Drought On The Germination of Maize Using PEG (Polyethylene Glycol) As A Substitute For Drought Screening
}

\author{
I. A. Dar*, Kamaluddin. Z. A. Dar, P.A. Sofi, and A.A.Lone \\ Division of GPB, FoA/RRS Wadura (SKUAST-Kashmir)- 193201
}

\begin{abstract}
Drought stress is one of the most important environmental factors in reduction of growth, development and production of plants. Germination of each seed is considered as one of the first and most fundamental life stages of a plant so that, the success in growth and yield production is also depending on this stage. To study the effect of PEG stress on germination and early seedling stages on maize, an experiment were laid out at laboratory conditions of Division of Genetics and Plant Breeding SKUAST-K FoA/RRS Wadura. This investigation was performed as factorial experiment under Complete Randomized Design (CRD) with three replications. Polyethylene glycol stress induced in laboratory caused progressive decline in both the parameters across all genotypes with increase in Polyethylene glycol from 0-20\% and both the parameters (length of radical and root biomass) had highest value under control.
\end{abstract}

Key Words: Drought, Germination, PEG, Length of Radical, Root Biomass

*Corresponding Author: Ishan Ahmad Dar (dareshan.786@gmail.com) 


\section{INTRODUCTION}

Maize (Zea mays L.) is an important cereal crop grown all over the world. Also, it is a stable food and commercial crop (Ti-da et al., 2006). On the other hand, drought stress is one of the most important environmental factors in reduction of growth, development and production of plants so, it is urgent to increase maize yields even under the unfavorable conditions. One of the most important abiotic factors limiting plant germination and early seedling stages is water stress brought about by drought and salinity, which are widespread problems around the world. Among the stages of the plant life cycle, seed germination, seedling emergence and establishment are the key processes in the survival and growth of plants (Hadas, 2004). Germination is regulated by duration of wetting and the amount of moisture in the growth medium (Schutz and Milberg 1997; Gill et al., 2002). Water stress acts by decreasing the percentage and rate of germination and seedling growth (Delachiave and De Pinho, 2003). Water stress not only affects seed germination but also increases mean germination time in crop plants (Willenborb et al., 2004).

Solutions of high molecular weight, polyethylene glycol (PEG), are often used to control water potential in seed germination studies (Hardegree and Emmerich, 1990). Polyethylene glycol compounds have been used to simulate osmotic stress effects in petri dish (in vitro) for plants to maintain uniform water potential throughout the experimental period. (Dodd and Donovan, 1999; Sidari et al., 2008). Induced water deficit by polyethylene glycol showed similar values to that observed in the field (Thill et al., 1979), permitting also vigour evaluation. In similar potential ranges, germination pattern may be different between species or even between varieties of the same species (Therios, 1982). Some species, as maize are sensitive to sodium chloride during germination. Polyethylene glycol of high molecular weight range (6000 or above) cannot inter the pores of plant cells (Oertli, 1985) and thus causes cytorrhysis rather than plasmolysis. Polyethylene glycol is also a better choice for imposing low water potential than the often used solute mannitol because mannitol has been shown to be taken up by plant cells and can cause specific toxic effects on growth (Hohl and Schopfer, 1991; Verslues et al., 1998). The principal aim of this study was to investigate the effects of osmotic stress generated by PEG on germination characteristics and early seedling growth of corn. 


\section{MATERIALS AND METHODS}

This study was performed at laboratory conditions of Division of Genetics and Plant Breeding SKUAST-K FoA Wadura with thirteen corn cultivar as factorial experiment under completely randomized design (CRD) with three replication. Effect of water stress was induced by different osmotic potential levels [0 (control), 10, 15 and $20 \%$ ] of PEG 6000 treatments on germination were studied. Thirteen varieties of maize were evaluated in the present study viz., Shalimar maize composite-4 (C-4), C-6, C-8, C-15, Shalimar maize composite -7 (KDM-72), Kishan Ganga-1 (KG-1), Kishan Ganga-2 (KG-2), Pratap Makka -3 (PM-3), Pratap Makka-4 (PM-4), Pratap Makka-5 (PM-5), Pratap Makka-Chari-6 (PM Chari-6), Aravali Makka-1 (AM1), Gujrat Makka-6 (GM-6). In each level of stress, sixteen seeds of any cultivar were selected and sterilized in sodium hypochlorite (1\%) and then washed in distilled water for two times. The seeds of corn were germinated in Petri dishes on 2 layers of filter paper in germinator maintained at $25^{\circ} \mathrm{C}$ and $75 \%$ humidity in darkness. Daily the need for, to replace the filter papers and add the PEG soluble was performed. After 7 days, germination percent was measured by International Seed Testing Association (ISTA) standard method. At the end of the seventh day, the length of radicle $(\mathrm{cm})$ and radicle weight $(\mathrm{g})$ of seeds were measured.

\section{RESULTS}

On the basis of analysis of variance results, the effect of stress levels on length of radicle (cm) and radicle weight $(\mathrm{g})$ were significant. Mean comparison results also revealed that the length of radicle and radicle weight under different stress levels were different.

1) Length of Radicle (cm): The data on length of radical under different levels of PEG-6000 showed following results (Table 1):

a. 0\% Level:- Under controlled conditions the length of radical was found highest in C-6 (20.33) followed by GM-6 (15.40) and AM-1 (13.10) and was lowest in PM-4 (4.66).

b. $10 \%$ Level:- Under $10 \%$ the length of radical was found highest in C-6 (14.86) followed by GM-6 (10.80) and KG-2 (9.76) and was lowest in PM Chari-6 (5.83).

c. $15 \%$ Level:- Under $15 \%$ the length of radical was found highest in C-6 (9.96) followed by AM-1 (9.93) and C-4 (9.56) and was lowest in KDM-72 (5.93). 
d. $20 \%$ Level:- Under $20 \%$ the length of radical was found highest in C-15 (7.23) followed by C-6 (7.00) and C-4 (6.21) and was lowest in KDM-72 (2.60).

2) Radicle Weight (g): The data on radicle weight under different levels of PEG-6000 showed following results (Table 2):

a. 0\% Level:- Under controlled conditions the root biomass was found highest in C-6 (0.863) followed by PM-5 (0.453) and PM Chari-6 (0.421) and was lowest in PM-4 (0.53).

b. $10 \%$ Level:- Under $10 \%$ the root biomass was found highest in C-6 (0.320) followed by KG1 (0.297) and PM-5 (0.270) and was lowest in PM-Chari-6 (0.103).

c. $15 \%$ Level:- Under $15 \%$ the root biomass was found highest in C-6 (0.248) followed by C-4 (0.209) and PM Chari-6 (0.203) and was lowest in KDM-72 (0.070).

d. $20 \%$ Level:- Under $20 \%$ the root biomass was found highest in C-15 (0.174) followed by PM-3 (0.171) and PM-5 (0.147) and was lowest in KDM-72 (0.030). 
Table 1: Effect of osmotic potential induced by PEG 6000 on length of radicle $(\mathrm{cm})$ of thirteen maize genotypes

\begin{tabular}{ccccc}
\hline & \multicolumn{4}{l}{ Length of Radicle (cm) } \\
\hline Genotypes & $\mathbf{0 \%}$ & $\mathbf{1 0 \%}$ & $\mathbf{1 5 \%}$ & $\mathbf{2 0 \%}$ \\
\hline Aravali Makka-1 & 13.100 & 6.267 & 9.933 & 2.867 \\
KDM-72 & 8.933 & 6.200 & 5.933 & 2.600 \\
C-6 & 20.333 & 14.867 & 9.967 & 7.000 \\
C-15 & 11.200 & 9.433 & 9.267 & 7.233 \\
C-8 & 11.200 & 8.533 & 6.333 & 5.333 \\
C-4 & 10.233 & 8.800 & 9.567 & 6.200 \\
PM-3 & 11.767 & 9.000 & 8.267 & 4.600 \\
PM-4 & 4.667 & 0.000 & 0.000 & 0.000 \\
PM-5 & 9.467 & 9.667 & 9.067 & 5.800 \\
KG-1 & 12.133 & 9.300 & 7.933 & 5.033 \\
KG-2 & 10.500 & 9.767 & 7.067 & 6.200 \\
PM Chari-6 & 11.933 & 5.833 & 9.033 & 4.400 \\
GM-6 & 15.400 & 10.800 & 8.767 & 4.700 \\
\hline Mean & $\mathbf{1 1 . 6 0 5}$ & $\mathbf{8 . 3 4 4}$ & $\mathbf{7 . 7 8 0}$ & $\mathbf{4 . 7 6 7}$ \\
\hline & & & & \\
\hline & & & & \\
\hline
\end{tabular}


Table 2: Effect of osmotic potential induced by PEG 6000 on radicle weight $(\mathrm{g})$ of thirteen maize genotypes.

\begin{tabular}{ccccc}
\hline & & \multicolumn{2}{c}{ Radicle Weight(g) } \\
\hline Genotypes & $\mathbf{0 \%}$ & $\mathbf{1 0 \%}$ & $\mathbf{1 5 \%}$ & $\mathbf{2 0 \%}$ \\
\hline Aravali Makka-1 & 0.420 & 0.123 & 0.183 & 0.051 \\
KDM-72 & 0.173 & 0.163 & 0.070 & 0.030 \\
C-6 & 0.863 & 0.320 & 0.248 & 0.113 \\
C-15 & 0.363 & 0.247 & 0.200 & 0.174 \\
C-8 & 0.207 & 0.193 & 0.083 & 0.077 \\
C-4 & 0.217 & 0.183 & 0.209 & 0.117 \\
PM-3 & 0.330 & 0.217 & 0.183 & 0.171 \\
PM-4 & 0.053 & 0.000 & 0.000 & 0.000 \\
PM-5 & 0.453 & 0.270 & 0.200 & 0.147 \\
KG-1 & 0.373 & 0.297 & 0.163 & 0.133 \\
KG-2 & 0.213 & 0.143 & 0.113 & 0.110 \\
PM Chari-6 & 0.421 & 0.103 & 0.203 & 0.073 \\
GM-6 & 0.287 & 0.247 & 0.150 & 0.120 \\
Mean & $\mathbf{0 . 3 3 6}$ & $\mathbf{0 . 1 9 3}$ & $\mathbf{0 . 1 5 4}$ & $\mathbf{0 . 1 0 1}$ \\
\hline & & & & \\
\hline
\end{tabular}




\section{Discussion}

Polyethylene glycol is the best solute that we are aware of for imposing a low water stress that is reflective of the type of stress Imposed by a drying soil (Verslues and Bray, 2004; Verslues et al., 1998; Van der Weele et al., 2000). Water stress due to drought is probably the most significant abiotic factor limiting plant and also crop growth and development. Drought stress is physiologically related, because it induces osmotic stress and most of the metabolic responses of the affected plants are similar to some extent. Water deficit affects the germination of seed and the growth of seedlings negatively. In present study, polyethylene glycol (PEG) compounds have been used to stimulate osmotic stress effects in Petri dish (In vitro) for plants to maintain uniform water potential throughout the experimental period. There was a progressive decline in both the parameters across all genotypes with increase in PEG levels from 0-20\% and both the parameters (Length of radical and radicle weight) had highest value under control (0\%) and had significant differences under water stress (Fig. 1 \& 2). The root length provides an important clue to the response of plants to drought stress. Water stress acts by decreasing the percentage and rate of germination and seedling growth as reported by Delachiave and De Pinho (2003) in senna, Farsiani and Ghobadi (2009) and Khayatnezhad et al. (2010) in corn, Gholamin and Khayatnezhad (2010) in wheat, and Mostafavi (2011) in safflower. There were reports in the literature of potential drought resistance traits like extensive viable rooting system that could explore deeper soil layers for water (Mirza, 1956; Bocev, 1963). Corn plants with more roots at seedling stage subsequently developed stronger root system, produced more green matter and had higher values for most characters determining seed yield (Bocev, 1963). This study strongly supports the assertion that germination indices can be utilized to screen maize for drought tolerance at germination and early seedling growth stage. There are many reports that are in agreement with the present findings indicating that drought stress severely reduces seed germination and early seedling growth. But the varieties having genetic potential to maintain the higher growth under stress conditions are drought tolerant. Water stress due to drought is probably the most significant abiotic factor limiting plant and also crop growth and development (Hartman et al., 2005). Growth of plants in arid and semi-arid land is dependent upon plants susceptibility to drought stress and also related to the ability of seeds to achieve optimum germination under these unfavorable conditions. Therefore, it is necessary to identify genotypes that are tolerance to drought at the primary growth stage. 


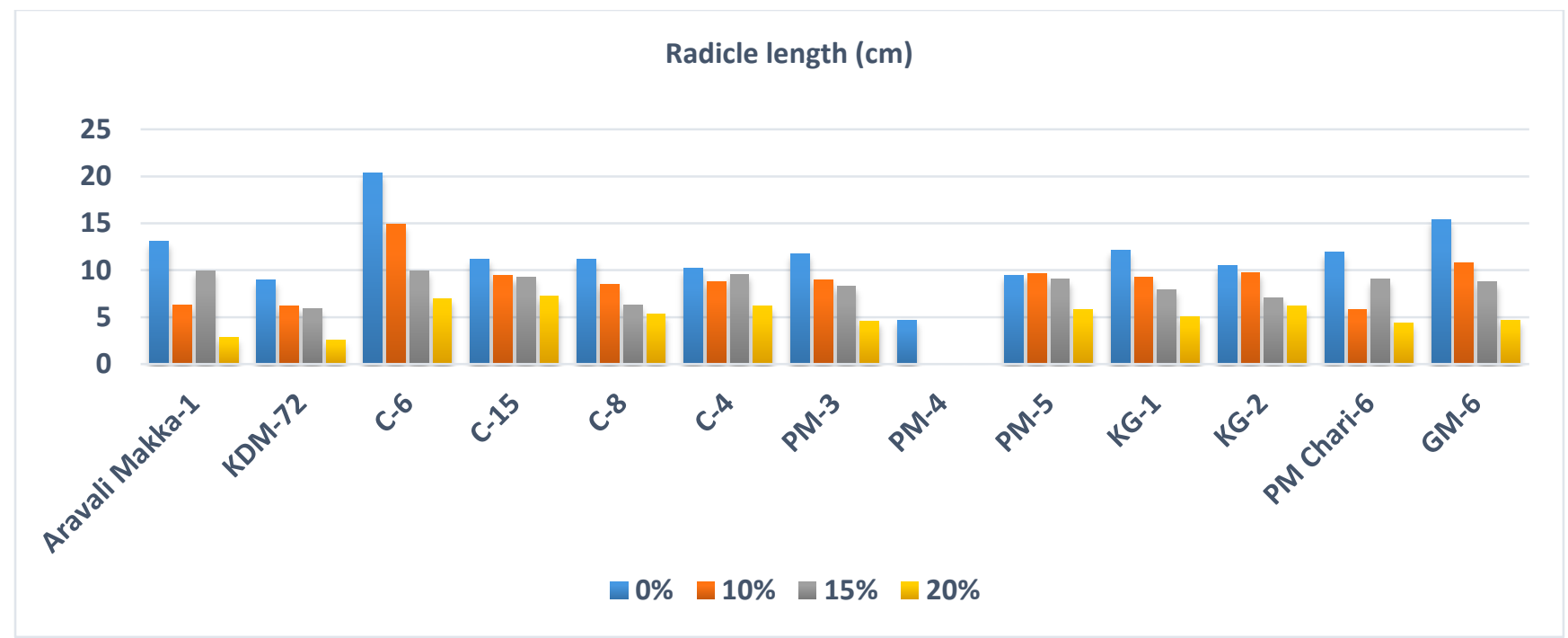

Fig. 1: Percentage of length of radicle affected by PEG

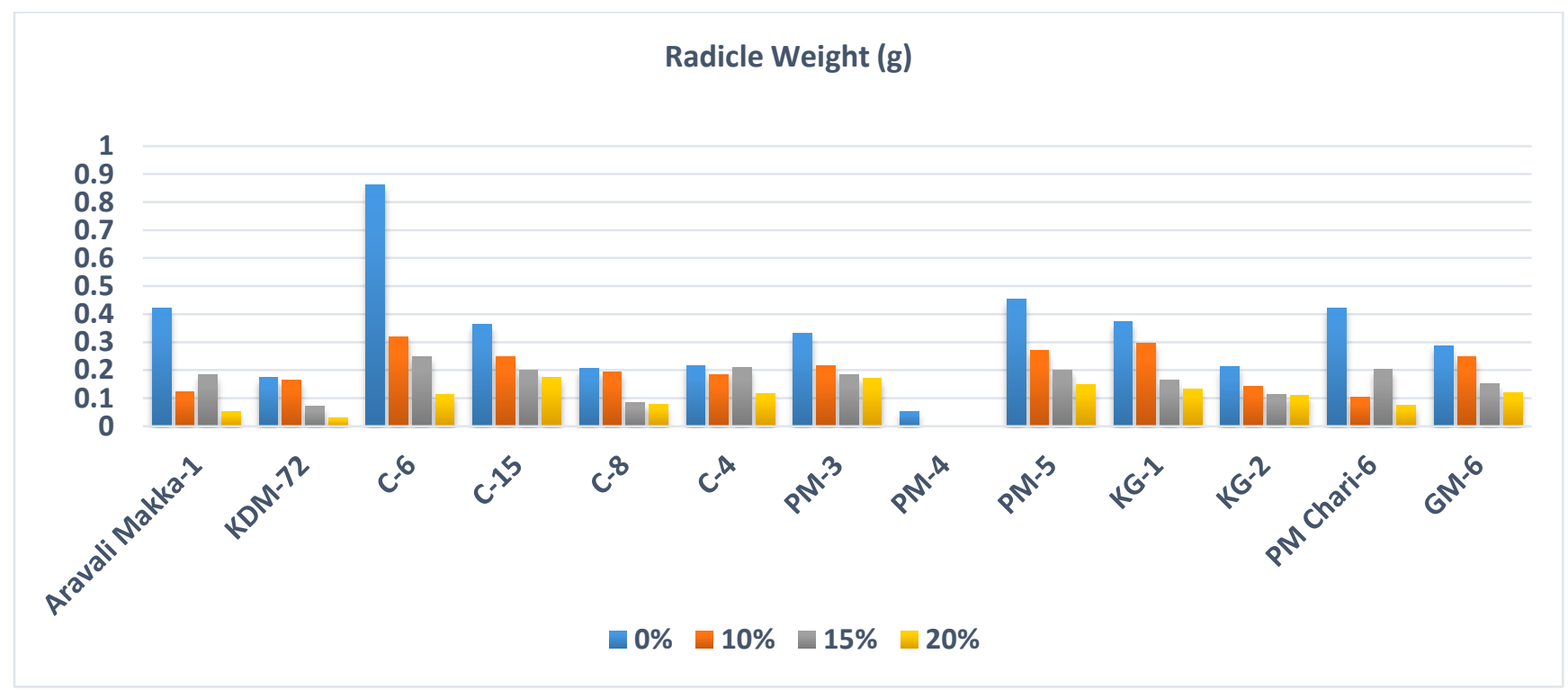

Fig. 2: Percentage of radicle weight affected by PEG 


\section{REFRENCES}

Bocev, B.V. 1963. Maize selection at an initial phase of development. Kukuruzu 1: p. 54.

Delachiave, M.E.A., De Pinho, S.Z. 2003. Germination of Senna occidentalis link: seed at different osmotic potential levels. Braz. Arch. Tech. 46: 163-166.

Dodd GL, Donovan LA (1999). Water potential and ionic effects on germination and seedling growth of two cold desert shrubs. Am. J. Bot. PMID: 10449394 86: 1146-1153.

Farsiani, A., Ghobadi, M.E. 2009. Effects of PEG and NaCl stress on two cultivars of corn (Zea mays L.) at germination and early seedling stages. World Acad. Sci. Eng. Tech. 57: 382385.

G. E. Ti-da., S. O. I. Fang- Gong- Sui., B. A. I. L. I. Ping., L.U. Yingyan and Zh. Guang-sheng 2006. Effect of water stress on the protective enzymes and lipid per oxidation in roots and leaves of summer maize. Agric. Sci, China vol. 5: 291-228.

Gholamin, R., Khayatnezhad, M. 2010. Effects of polyethylene glycol and $\mathrm{NaCl}$ stress on two cultivars of wheat (Triticum durum) at germination and early seeding stages. American Eurasian J. Agric. Environ. Sci. 9(1): 86-90.

Gill, R.K., Sharma, A.D., Singh, P., Bhullar, S.S. 2002. Osmotic stress induced changes in germination, growth and soluble sugar content of Sorghum bicolor (L.) Moench seeds. Bulg. J. Plant. Physiol. 28: 12-25.

Hadas, A. 2004. Seedbed Preparation: The Soil Physical Environment of Germinating Seeds. In: Handbook of Seed Physiology: Applications to Agriculture, Benech-Arnold RL and Sanchez RA(Eds.). Food Product Press, New York, ISBN: 1560229292, p. 480.

Hardegree, S.P., Emmerich, W.E. 1990. Effect of polyethylene glycol exclusion on the water potential of solution-saturated filter paper. Plant Physiol. PMID: 16667298. 92: 462-466.

Hohl, M., Schopfer, P. 1991. Water relations of growing Maize coleoptiles comparison between Mannitol and Polyethylene glycol 6000 as external osmotica for adjusting turgor pressure. Plant Physiology 95(3), pp.716-722. 
Khayatnezhad, M., Gholamin, R., Jamaatie-Somarin, S.H., Zabihi- Mahmoodabad, R. 2010. Effects of peg stress on corn cultivars (Zea mays L.) at germination stage. World Appl. Sci. J. 11(5): 504-506.

Delachiave, M. E. A., De Pinho, S. Z. 2003. Germination of Senna occidentalis link: seed at different osmotic potential levels. Braz. Arch. Techn 46: 163-166.

Mirza, O.K. 1956. Relationship of root development to drought resistance of plants. Indian J. Agron 1: 41-46.

Mostafavi, K.H. 2011. An evaluation of safflower genotypes (Carthamus tinctorius L.), seed germination and seedling characters in salt stress conditions. Afr. J. Agric. Res. 6(7): 1667-1672.

Oertli, J.J. 1985. The response of plant cells to different forms of moisture stress. Journal of plant physiology 121(4): 295-300.

Schutz, W., Milberg, P. 1997. Seed germination in Launaea arborescens: a continuously flowering semi-desert shrub. J. Arid Environ. 36: 113-122.

Sidari, M., Mallamaci, C., Muscolo, A. 2008. Drought, salinity and heat differently affect seed germination of Pinus pinea. J. For. Res 13: 326-330.

T. Hartmann., M. College., P. Lumsden. 2005. Responses of different varieties of Lolium perenne to salinity. Annual Conference of the Society for Experimental Biology, Lancashire.

Therios, L. N. (1982). Effects of temperature, moisture stress and $\mathrm{pH}$ on the germination of seeds of amond (Prunus amygdalus "Truioto"). Seed Science and Technology 10: 5885-5894.

Thill, D. C., Schimman, R.D., Appeby, A.P. (1979). Osmotic stability of mannitol and polethyleneglycol 20.000 solutions used as seed germination media. Agronomy Journal 71: 105-108.

van der Weele, C.M., Spollen, W.G., Sharp, R.E., Baskin, T.I. 2000. Growth of Arabidopsis thaliana seedlings under water deficit studied by control of water potential in nutrientagar media. Journal of Experimental Botany 51(350): 1555-1562. 
Verslues, P.E., Bray, E.A. 2004. LWR1 and LWR2 are required for osmoregulation and osmotic adjustment in Arabidopsis. Plant Physiology 136(1): 2831-2842.

Verslues, P.E., Ober, E.S., Sharp, R.E. 1998. Root growth and oxygen relations at low water potentials. Impact of oxygen availability in polyethylene glycol solutions. Plant Physiology 116(4): 1403-1412.

Willenborb, C.J., Gulden, R.H., Jhonson, E.N., Shirtliffe, S.J. 2004. Germination characteristics of polymer-coated canola (Brassica napus L.) seeds subjected to moisture stress at different temperatures. Agron. J. 96: 786-791. 